\title{
Effects of Heat Treatment and Chemistry on the Long-Term Phase Stability of a High Strength Nickel-Based Superalloy
}

\author{
P. W. Keefe, S. O. Mancuso \& G. E. Maurer \\ Special Metals Corporation \\ New Hartford, NY
}

\begin{abstract}
Phase stability of UDIMET ${ }^{\circledR}$ alloy 720 (U720), a high strength, hot corrosion resistant alloy was studied as a function of chemistry, processing, heat treatment, and service temperature. U720 is relatively stable with respect to sigma phase when given a supersolvus heat treatment which results in a coarse grain creep resistant microstructure. When $\mathrm{U} 720$ is given a subsolvus heat treatment to preserve a fine grain high strength microstructure rapid precipitation of a globular grain boundary sigma phase occurs during $760^{\circ} \mathrm{C}$ exposure. This precipitation is associated with a degradation in tensile ductility, creep resistance and toughness. As much as a $60 \%$ reduction in initial tensile ductility was observed after 1000 hours of exposure while room temperature charpy $v$-notch impact strengths were reduced from 22 to $6 \mathrm{ft}$. 1b. A modified version of UDIMET alloy 720LI (U72OLI) was found to be substantially less prone to precipitation of sigma phase in fine grain product. U720LI maintains tensile properties and only suffers minor degradation in ductility after 1000 hours exposure at $760^{\circ} \mathrm{C}$.
\end{abstract}

- Registered Trademark of Special Metals Corporation

Superalloys 1992

Edited by S.D. Antolovich, R.W. Stusrud, R.A. MacKay,

D.L. Anton, T. Khan, R.D. Kissinger, D.L. Klarstrom

The Minerals, Metals \& Materials Society, 1992 


\section{Introduction}

U720, a wrought nickel-based superalloy, was originally developed for land-based turbine applications. It was specifically designed for long-term service in excess of 10000 hours at temperatures up to $900^{\circ} \mathrm{C}$. Its chemistry was balanced to achieve a unique combination of mechanical and physical properties, including tensile strength, creep resistance, fracture toughness, structural stability and hot corrosion resistance. Optimum creep properties were achieved by fully solutioning $\gamma^{\prime}$ and partially solutioning carbides and borides followed by a three-step aging treatment to establish a duplex distribution of $\gamma^{\prime}$ and discrete, stable grain boundary precipitates. Grain sizes were typically ASTM 1-0. Susceptibility to sigma phase formation was closely monitored and the final chemistry was selected to minimize sigma phase formation at operating conditions.

Interest in $\mathrm{U} 720$ as a potential high strength disk alloy arose because of its remarkable combination of blade mechanical properties and its excellent workability experienced by forgers ${ }^{(1)}$. To evaluated $\mathrm{U} 720$ as a disk material, forging parameters were adjusted to develop a fine grain structure. Subsequent evaluations found that fine grain U720 exhibited mechanical properties approaching those of advanced powder metallurgy superalloys ${ }^{(1,2)}$.

Coarse grain U720 was designed to be free of deleterious amounts of sigma phase after prolonged exposure at $815-840^{\circ} \mathrm{C}$. Field experience of blades exposed in this temperature range revealed only minor precipitation of Widmanstätten-like sigma phase after thousands of service hours. Typical aging responses in superalloys generally predict that the time required to precipitate sigma at $760^{\circ} \mathrm{C}$ is an order of magnitude larger than that observed at $840^{\circ} \mathrm{C}^{(3)}$. Therefore, if only trace amounts of sigma phase were observed after long-term exposure at $815-840^{\circ} \mathrm{C}$, it was believed that $U 720$ should possess relatively good phase stability when exposed at $760^{\circ} \mathrm{C}$. Because of these observations, the development of sufficient quantities of sigma phase to cause mechanical property degradation was unexpected.

Fine grain U720 is partially solution treated to re-dissolve as much $\gamma^{\prime}$ as possible without causing grain coarsening. Subsequent aging treatments precipitate a uniform dispersion of fine $\gamma^{\prime}$ in the matrix along and chromium carbide/boride, $\mathrm{M}_{23}(\mathrm{C}, \mathrm{B})_{6}{ }^{(2)}$, in the grain boundaries. Excellent mechanical properties were measured in the as-heat treated condition but rapid degradation in creep properties were noted when material was exposed at $760^{\circ} \mathrm{C}$ for more than a hundred hours. Initial metallographic examinations did not immediately identify the problem. Sigma phase was forming in the grain boundaries in a morphology consistent with that of chromium carbide. The morphology was globular and under light optics was nearly impossible to detect. Under electron optics, the contrast between sigma phase and carbide phases was sufficient to reveal the extent of sigma phase precipitation. The presence and morphology of sigma phase was consistent with previous reports of sigma phase precipitation ${ }^{(3)}$. The lattice structure of sigma phase is quite similar to that of $\mathrm{M}_{23} \mathrm{C}_{6}$ and carbide interfaces have been reported to be preferred initiation sites for sigma precipitation $^{(4)}$. 
The objective of this study was to document the conditions in which sigma phase appears in this class of alloy and to demonstrate the chemistry modifications that were necessary to alleviate the deleterious condition. Through very straightforward changes in chemistry, a U720 composition was selected that eliminated the precipitation of sigma phase. The chemistry now used for fine grain applications, U720LI, is very stable and has not suffered degradation in mechanical strength or workability due to changes in composition.

\section{Experimental Procedures}

Initial experiments were designed to show the effects of time, temperature and heat treatment on the precipitation and morphology of sigma phase in U720. Samples were subsolvus heat treated (listed in Table I) and exposed at $750^{\circ} \mathrm{C}$ for $50,200,500$ and 1000 hours respectively. Additional subsolvus heat treated samples were exposed at $843^{\circ} \mathrm{C}$ for 20 hours and at $704^{\circ} \mathrm{C}$ for 300 hours. For comparison a second set of U720LI samples was subsolvus heat treated and given the same exposures as above. U720LI contained slightly lower levels of chromium, carbon and boron (Table II).

Table I Heat Treatments Evaluated

\begin{tabular}{|c|r|}
\hline SUBSOLVUS H.T. & SUPERSOLVUS H.T. \\
\hline $1105^{\circ} \mathrm{C}-2 \mathrm{HrS}-\mathrm{OQ}$ & $1168^{\circ} \mathrm{C}-4 \mathrm{HrS}-\mathrm{AC}$ \\
$760^{\circ} \mathrm{C}-8 \mathrm{HrS}-\mathrm{AC}$ & $1079^{\circ} \mathrm{C}-4 \mathrm{HrS}-\mathrm{AC}$ \\
$649^{\circ} \mathrm{C}-24 \mathrm{HrS}-\mathrm{AC}$ & $843^{\circ} \mathrm{C}-24 \mathrm{HrS}-\mathrm{AC}$ \\
& $760^{\circ} \mathrm{C}-16 \mathrm{HrS}-\mathrm{AC}$ \\
\hline $\mathrm{OQ}=$ Oil Quench, $\mathrm{AC}=\mathrm{Air} \mathrm{COOl}$
\end{tabular}

Table II Nominal Chemistries of U720 and U720LI (wt\%)

\begin{tabular}{|l|c|c|c|c|c|c|c|c|c|}
\hline & $\mathrm{C}$ & $\mathrm{Cr}$ & $\mathrm{Co}$ & $\mathrm{Mo}$ & $\mathrm{W}$ & $\mathrm{Ti}$ & $\mathrm{Al}$ & $\mathrm{B}$ & $\mathrm{Zr}$ \\
\hline \hline $\mathrm{U} 720$ & 0.035 & 18.0 & 14.7 & 3.0 & 1.25 & 5.0 & 2.5 & 0.033 & 0.03 \\
\hline U720LI & 0.010 & 16.0 & 14.7 & 3.0 & 1.25 & 5.0 & 2.5 & 0.015 & 0.03 \\
\hline
\end{tabular}

Data for supersolvus heat treated $U 720$ was taken from a series of unpublished special Metals Corporation company reports ${ }^{(5-8)}$. Data at $899^{\circ} \mathrm{C} / 500$ hours and $750^{\circ} \mathrm{C} / 200$ hours was taken from heat treated test blanks. The balance of the supersolvus heat treated data was taken from stress rupture bars. Time and temperature of the test was considered to be the heat treatment time and temperature.

Following thermal exposure, all samples were metallographically prepared for microstructural observations using a scanning electron microscope (SEM) and particle identifications using insitu energy dispersive spectroscopy (EDS) analysis. 
Samples of U720 and U720LI were also analyzed by phase extraction techniques. $\gamma$ and $\gamma^{\prime}$ phases were selectively dissolved leaving a residue of carbides, borides and sigma phase. This residue was subsequently evaluated using $X$-ray diffraction methods to identify phases present and determine their relative concentrations. Relative concentration values were calculated from $\mathrm{X}$-ray peak intensities and roughly corresponded to concentrations of the phases in the residue. They should not be considered absolute values. Samples in the as-rolled, as-rolled plus $1104^{\circ} \mathrm{C}-6 \mathrm{Hrs}-$

$A C$, subsolvus heat treated and subsolvus heat treated plus $1104^{\circ} \mathrm{C}$ - 6 Hrs - AC were analyzed by these methods. Each condition was evaluated after exposure at $704^{\circ} \mathrm{C}$ for 500 hours and $843^{\circ} \mathrm{C}$ for 20 hours respectively.

Six samples (three from each composition) were prepared for SEM/EDS analysis to further understand the microstructural conditions present prior to and after the precipitation of sigma phase. Samples were evaluated in the as-rolled condition, after subsolvus heat treatment and after subsolvus heat treatment and exposure to $750^{\circ} \mathrm{C}$ for 1000 hours. Chemical analysis of the coarse $\gamma^{\prime}$, grain boundaries and $\gamma$ phases was performed on the samples to determine the chemical profiles of sigma phase forming elements as a function of material condition.

The influence of exposure time at $750^{\circ} \mathrm{C}$ on the mechanical properties of U720 and U720LI was evaluated. Room temperature tensile, $750^{\circ} \mathrm{C}$ notch stress rupture at $448 \mathrm{MPa}$ and room temperature impact tests were performed on samples following subsolvus heat treatment and thermal exposure at $750^{\circ} \mathrm{C}$ for 0 (asheat treated), 200, 500, 1000 and 1500 hours respectively.

\section{Results}

The effect of heat treatment on the stability of $\mathrm{U} 720$ is illustrated in Figure 1. Material supersolvus heat treated exhibited small amounts of sigma phase after approximately 400 hours at $843^{\circ} \mathrm{C}$. These precipitates were found to be the classic widmanstätten-type sigma phase morphology (Figure 2a). No sigma phase was observed in material exposed to temperatures at or above $871^{\circ} \mathrm{C}$. The rate of sigma phase formation was considerably higher for fine grain material. Heavy concentrations of globular sigma phase (Figure 2b) were observed after only 20 hours at $843^{\circ} \mathrm{C}$. The sample exposed to $760^{\circ} \mathrm{C}$ for 50 hours also exhibited moderate to heavy concentrations of sigma phase. The only subsolvus heat treated sample that did not precipitate sigma phase was the sample exposed at $704^{\circ} \mathrm{C}$ for 500 hours.

The results of the phase extraction analysis on U720 are 1 isted in Table III. Results indicated as-rolled samples precipitated the greatest amount of sigma phase. All thermal treatments prior to exposure resulted in a substantial reduction in the amount of sigma phase precipitated. Subsolvus heat treated samples precipitated the least amount of sigma phase. U720LI samples exhibited predominantly $\mathrm{M}_{23}(\mathrm{C}, \mathrm{B})_{6}$ carbides and small amounts of $\mathrm{MB}_{2}$ and or $\mathrm{M}_{3} \mathrm{~B}_{2}$ borides, but no sigma phase. 


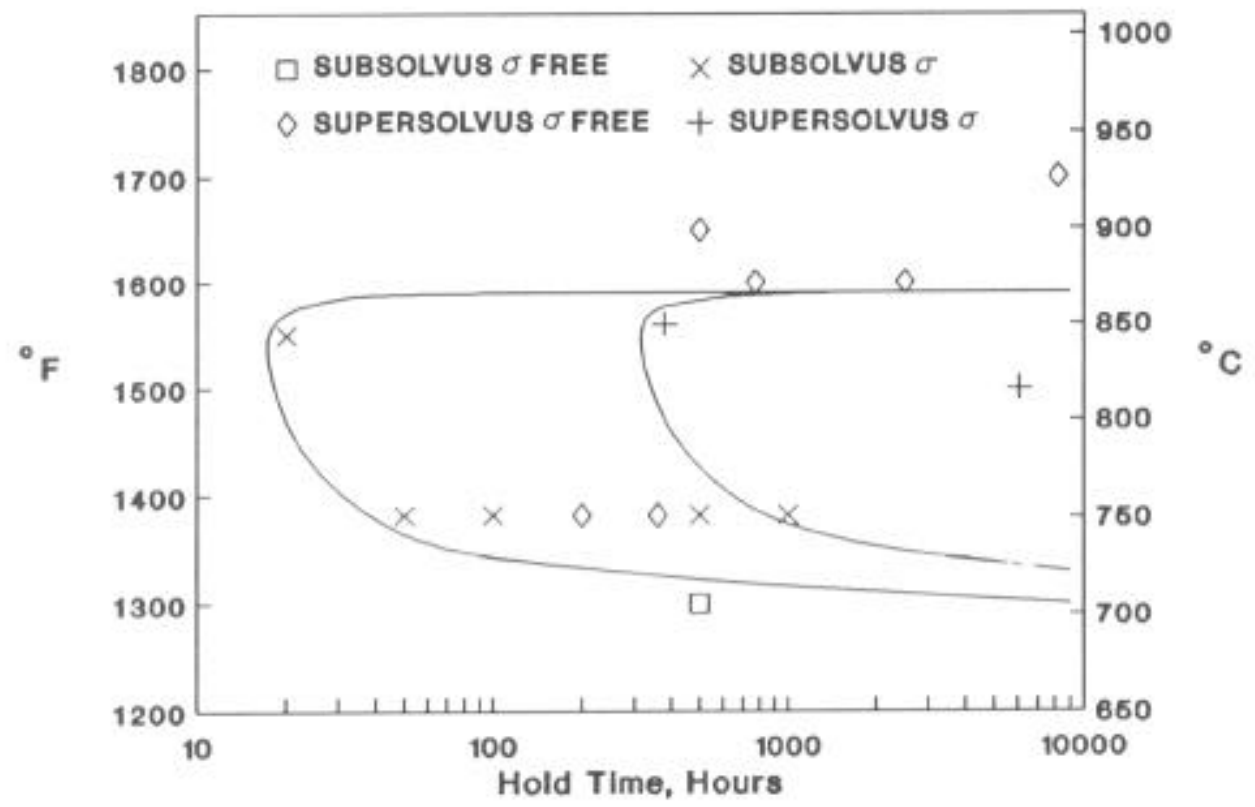

Figure 1 The effect of heat treatment and temperature on the rate of sigma phase precipitation for U720.
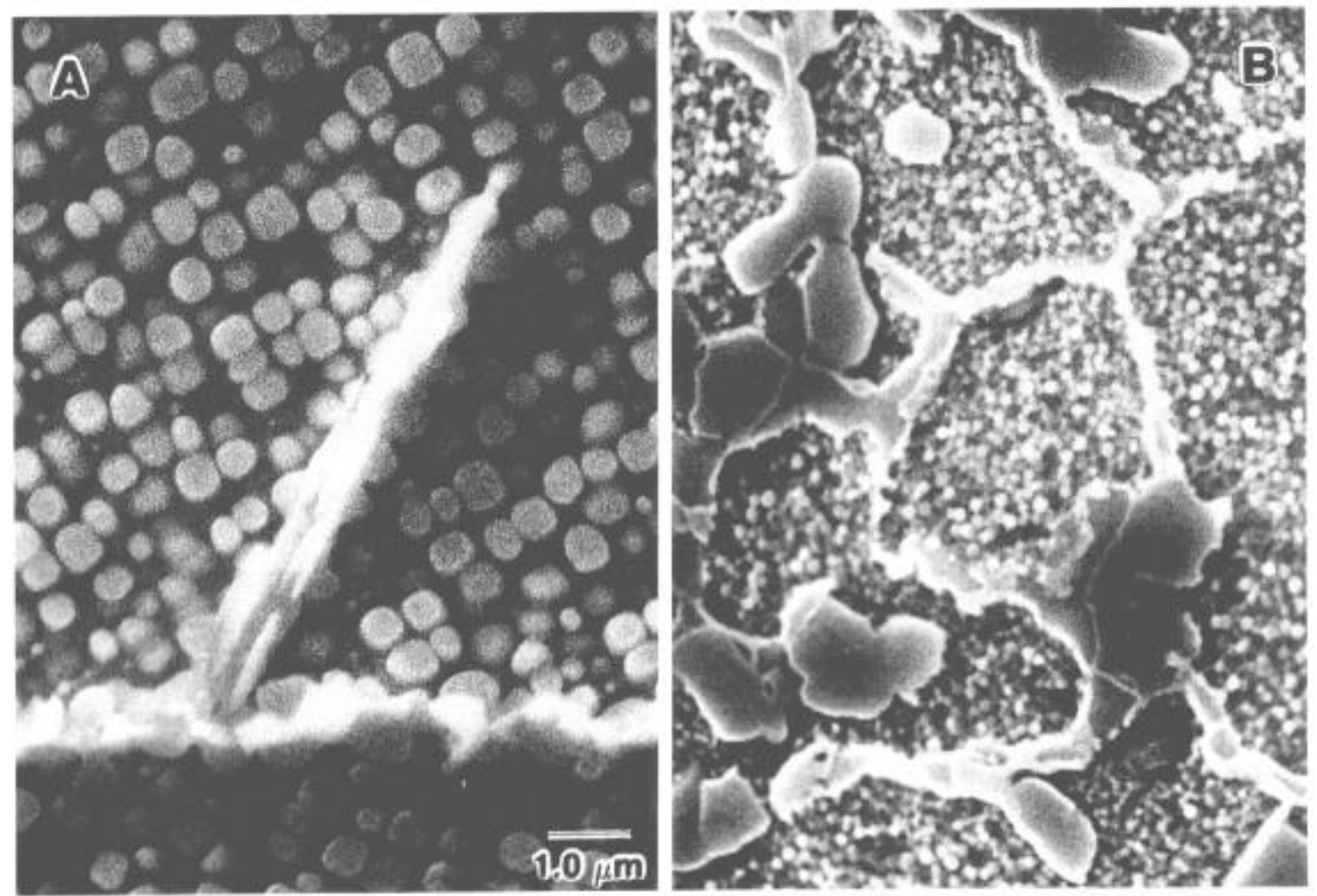

Figure 2 The effect of heat treatment on the morphology of sigma phase in U720 a) supersolvus heat treatment (Widmanstätten), b) subsolvus heat treatment (globular). 
Table III Phase Extraction Results of U720 and U720LI.

\begin{tabular}{|c|ccccc|ccccc|}
\hline U720 & \multicolumn{5}{|c|}{$704^{\circ} \mathrm{C}-500 \mathrm{HrS}$} \\
\hline $\begin{array}{c}\text { AS } \\
\text { ROLLED }\end{array}$ & 25 & 21 & 40 & 13 & - & 5 & 7 & 26 & 62 & - \\
\hline $\begin{array}{l}\text { ROLLED }+ \\
1104 \mathrm{C}-6\end{array}$ & 28 & 18 & 44 & - & 9 & 22 & 17 & 29 & 33 & - \\
\hline $\begin{array}{c}\text { SUBSOLVUS } \\
\text { HT }\end{array}$ & 23 & 22 & 55 & - & - & 23 & 24 & 37 & 16 & - \\
\hline $\begin{array}{c}\text { SUBSOLVUS } \\
+ \text { 1104C-6 }\end{array}$ & 22 & 23 & 56 & - & - & 15 & 15 & 55 & 11 & 3 \\
\hline
\end{tabular}

\begin{tabular}{|c|c|c|c|c|c|c|c|c|c|c|}
\hline U720LI & TiC & $\begin{array}{r}704^{\circ} \mathrm{C} \\
\mathrm{M}_{3} \mathrm{~B}_{2}\end{array}$ & $\mathrm{M}_{23} \mathrm{C}$ & $\begin{array}{l}\text { rs } \\
\text { SMA }\end{array}$ & $\mathrm{MB}_{2}$ & TiC & $\begin{array}{r}843 \\
M_{3} B_{2}\end{array}$ & $\begin{array}{l}{ }^{\circ} \mathrm{C}- \\
\mathrm{M}_{23} \mathrm{C}_{6}\end{array}$ & $\begin{array}{l}20 \mathrm{HrS} \\
\text { SIGMA }\end{array}$ & $\mathrm{MB}_{2}$ \\
\hline $\begin{array}{c}\text { AS } \\
\text { ROLLED }\end{array}$ & - & - & 100 & - & - & - & 11 & 69 & - & 19 \\
\hline $\begin{array}{l}\text { ROLLED + } \\
1104 \mathrm{C}-6\end{array}$ & - & - & 100 & - & - & & & & & \\
\hline $\begin{array}{c}\text { SUBSOLVUS } \\
\text { HT }\end{array}$ & - & - & 72 & - & 28 & - & - & 88 & - & 13 \\
\hline $\begin{array}{l}\text { SUBSOLVUS } \\
+\quad 1104 \mathrm{C}-6\end{array}$ & - & 14 & 86 & - & - & & & & & \\
\hline
\end{tabular}

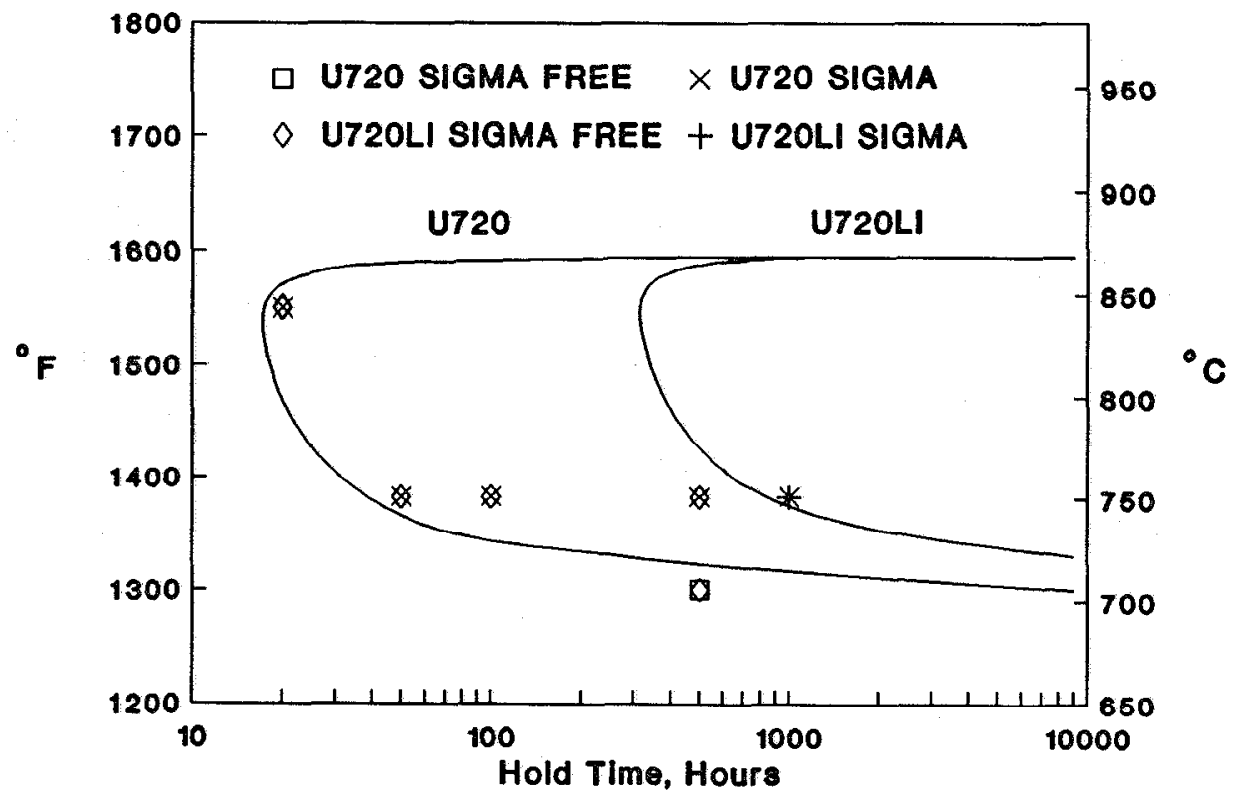

Figure 3 The effect of composition on the precipitation of sigma phase in subsolvus heat treated material. 
Figure 3. illustrates the effect of composition on sigma phase precipitation in subsolvus heat treated material. Results for U720 and U720LI are plotted on the same figure for comparison. U720LI samples did not exhibit sigma phase except the sample exposed for 1000 hours at $760^{\circ} \mathrm{C}$. This sample contained only light concentrations of globular sigma phase.

A comparison of general microstructures of U720 and U720LI in the as-heat treated condition and after 1000 hours at $760^{\circ} \mathrm{C}$ is presented in Figure 4. Microstructures of the as-heat treated samples are essentially identical for both compositions. Both contain very coarse $\gamma^{\prime}$ precipitates which pin grain boundaries, even dispersions of very fine $\gamma^{\prime}$ precipitates throughout the matrix and very few grain boundary carbides. After exposure both materials exhibited coarsening of very fine $\gamma^{\prime}$ particles. U720 also exhibited a substantial increase in the amount of grain boundary precipitates in the form of $\mathrm{M}_{23}(C, B)_{6}$ and sigma phase.
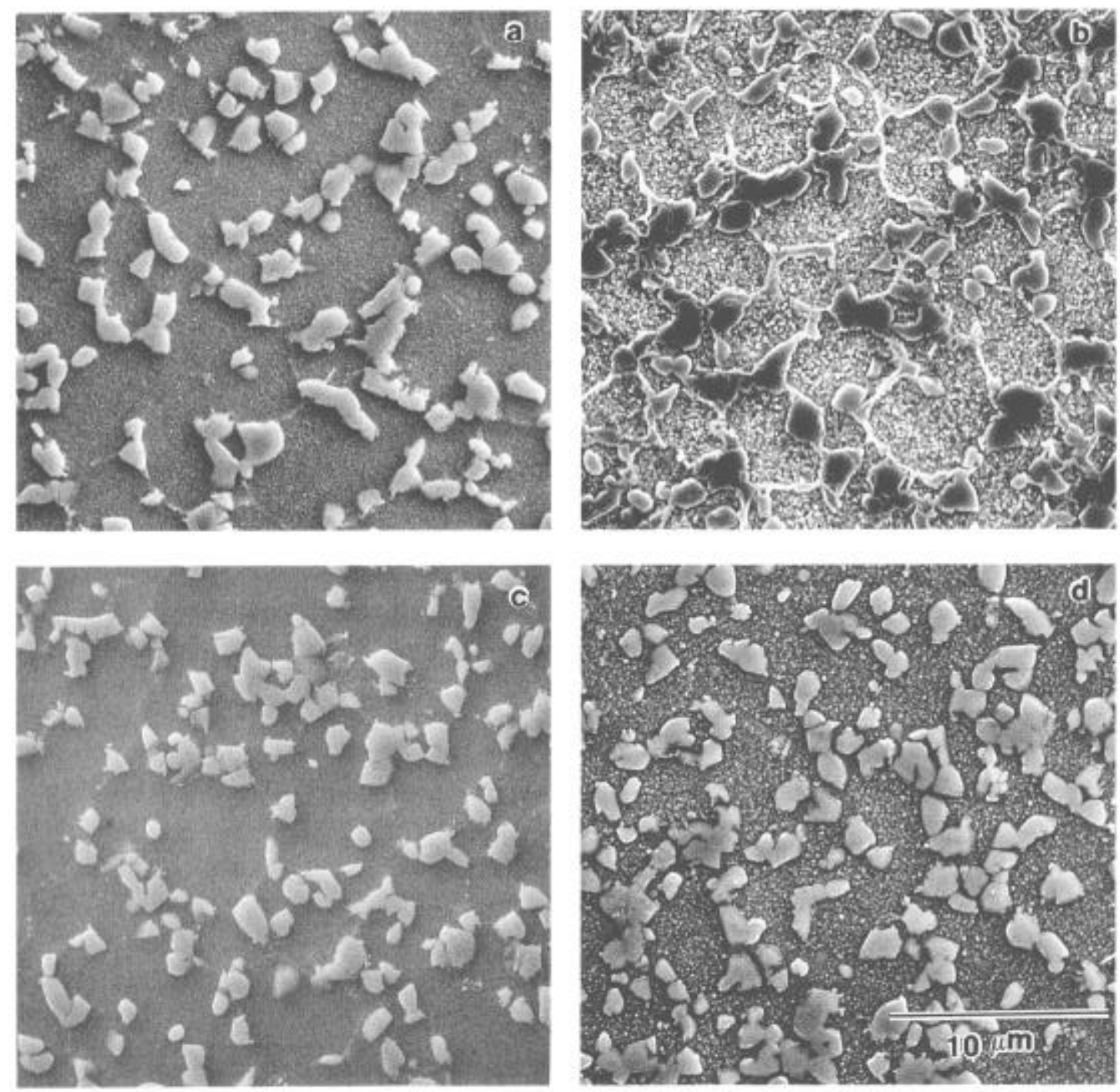

Figure 4 Effect of thermal exposure on microstructures of subsolvus heat treated U720 and U720LI a) U720 as-heat treated, b) $\mathrm{U} 720$ plus $750^{\circ} \mathrm{C}-1000 \mathrm{hrs}$, c) U720LI asheat treated and d) U720LI plus $750^{\circ} \mathrm{C}-1000 \mathrm{hrs}$. 
SEM/EDS analysis was unable to find $\mathrm{Cr}$ enrichment near coarse $\gamma^{\prime}$ precipitates in as-rolled samples. In general, the center of the grains contained equivalent or slightly higher levels of $\mathrm{Cr}$.

Figure 5. illustrates the effect of $750^{\circ} \mathrm{C}$ exposures up to 1500 hours on room temperature $0.2 \%$ yield strength and percent elongation. Thermal exposure did not markedly affect the yield strength of either alloy. The strength of the U720LI did appear to decrease slightly (approximately $70 \mathrm{MPa}$ ) and was typically 30 to $70 \mathrm{MPa}$ lower than U720. The effect of exposure on ductility (\% elongation and \% reduction in area) was more pronounced. U720LI exhibited a gradual reduction in percent elongation, from $23 \%$ to approximately $17 \%$, with exposure. U720 exhibited relatively low elongation results (approximately $12 \%$ ) in the as-heat treated condition. Elongation rapidly decreased with thermal exposure and reached a level of approximately 3\% after 1000 hours. The same trends were observed in the percent reduction of area.

Figure 6. illustrates the effect of thermal exposure and composition on charpy impact properties. These results generally mirror the ductility results. $\quad 0720$ exhibits initially low properties which rapidly decrease with increased thermal exposure, while the U720LI composition exhibits a gradual decrease in properties.

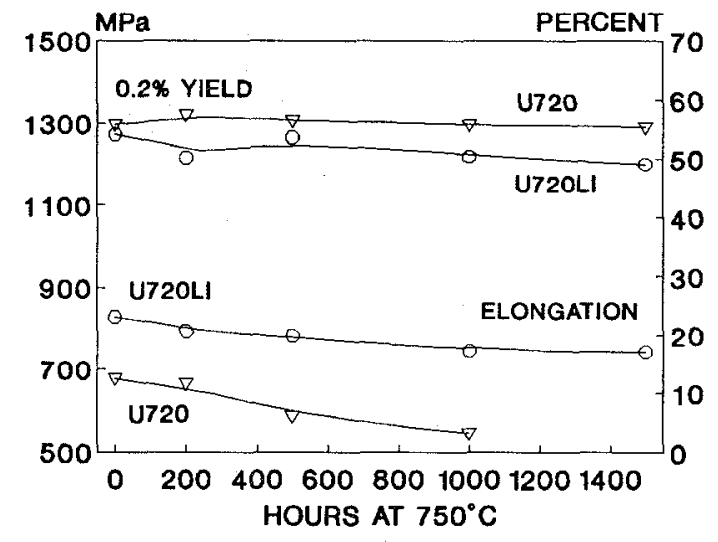

Figure 5 Effect of exposure time at $750^{\circ} \mathrm{C}$ on the room temperature $0.2 \%$ yield strength and $\%$ elongation of U720 and U720LI.

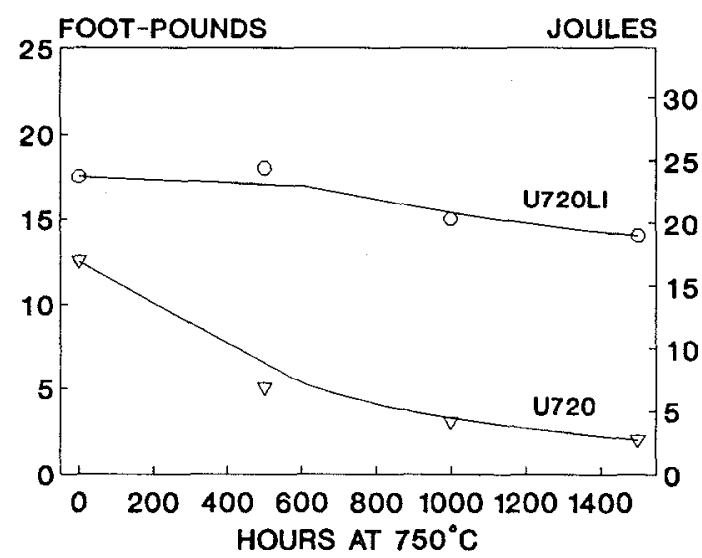

Figure 6 Effect of exposure time at $750^{\circ} \mathrm{C}$ on room temperature charpy impact properties of U720 and U720LI.

\section{Discussion}

It was originally believed that the propensity of subsolvus heat treated $\mathrm{U} 720$ to precipitate sigma phase was related to an enrichment of $\mathrm{Cr}$ adjacent to very coarse $\gamma^{\prime}$ precipitates (2-4 microns). This high $\mathrm{Cr}$ region, formed by the expulsion of $\mathrm{Cr}$ from the coarsening $\gamma^{\prime}$, was thought to be a reservoir of $\mathrm{Cr}$ for the 
precipitation of both $\mathrm{M}_{23}(\mathrm{C}, \mathrm{B})_{6}$ and sigma phase. This model was consistent with the observations that supersolvus heat treatment or extended subsolvus treatments near the $\gamma^{\prime}$ solvus temperature substantially reduced the susceptibility of U720 to precipitate sigma phase, in that these thermal cycles reduce or eliminate the $\mathrm{Cr}$ enrichment through diffusion. However, EDS analysis of as rolled U720 and U72OLI was not able to detect any elevation in the level of $\mathrm{Cr}$ near coarse $\gamma^{\prime}$ precipitates; in fact, $\mathrm{Cr}$ concentrations were found to be higher in the center of the grain away from the coarse $\gamma^{\prime}$. It is possible that a small gradient or one which occurs over a narrow region could be missed by the techniques used. The smallest area that could be analyzed was approximately one micron in diameter. In addition, analysis of areas close to the $\gamma^{\prime}$ precipitates are likely to pick up interference from the $\gamma^{\prime}$. Due to large difference in Cr content of the $\gamma^{\prime}$ and the $\gamma$ phases this could conceivably mask the gradient.

One observation which supports the absence of a gradient is that during conversion of the ingot to billet, $\gamma^{\prime}$ is slowly coarsened by many repetitive hot work and reheat operations at approximately $1090^{\circ} \mathrm{C}$. The time at temperature of these operations is substantially longer than the six hour heat treatment at $1104^{\circ} \mathrm{C}$; therefore, the effect of the six hour heat treatment on homogeneity should be minimal. This suggests that a mechanism other than $\mathrm{Cr}$ enrichment produces the accelerated sigma phase precipitation.

Based on these observations the following model is proposed for the formation of sigma phase and $M_{23}(C, B)_{6}$ in subsolvus heat treated $\mathrm{U720}$. With exposure to temperatures in the range of $750^{\circ} \mathrm{C}$ to $850^{\circ} \mathrm{C}$, U720 precipitates $\mathrm{M}_{23}(\mathrm{C}, \mathrm{B})_{6}$ at the grain boundaries. This precipitation is accelerated by the fine grain size (5 to 10 microns) through rapid diffusion along grain boundaries, short diffusion distances to grain boundaries and retained hot work deformation. As exposure times increase, this carbide coarsens into a continuous globular morphology and sigma phase precipitates along grain boundaries adjacent to coarse $\gamma^{\prime}$ precipitates. The rate at which this process occurs appears to increase with an increase in retained hot work deformation. As a result, thermal treatments which anneal the alloy reduce the amount of sigma phase observed by reducing the rate of precipitation. This is consistent with the results of Table III and the fact that U720 is least prone to the precipitation of sigma phase in the supersolvus heat treated condition. This model assumes sufficient $\mathrm{Cr}$ is available in the matrix to precipitate sigma phase (i.e. no Cr gradient is necessary). Therefore, the stability of U720LI results from insufficient $\mathrm{Cr}$ to complete the sigma phase precipitation. Like wise very few $\mathrm{M}_{23}(\mathrm{C}, \mathrm{B})_{6}$ type carbides precipitate during exposure due to low levels of $C$ and $B$.

The effect of thermal exposure on mechanical properties is relatively straightforward. Precipitation of a continuous or semi-continuous brittle phase at the grain boundaries seriously degrades ductility. In this case, $\mathrm{M}_{23}(C, B)_{6}$ and sigma phase are the precipitates. 


\section{Conclusions}

1) The rate of globular sigma phase precipitation in subsolvus heat treated $\mathrm{U} 720$ appears to be increased by increasing retained hot work deformation and this reaction is aided by fine grain structure.

2) Ductility degradation of subsolvus heat treated 0720 with exposure to temperatures in the range of $750-850^{\circ} \mathrm{C}$ is the result of excessive precipitation of $\mathrm{M}_{23}(\mathrm{C}, \mathrm{B})_{6}$ and sigma phase at grain boundaries.

3) A reduction in $\mathrm{Cr}, \mathrm{C}$ and $\mathrm{B}$ improves phase stability and eliminates ductility degradation in $\mathrm{U} 720$.

4) The new alloy composition designated U720LI has disk alloy capability.

\section{Acknowledgements}

The authors gratefully acknowledge W.J. Boesch for his critique of the manuscript and technical discussions. We also thank J.F. Radavich for his technical assistance.

\section{References}

1) F.E. Sczerzenie and G.E. Maurer, "Development of UDIMET 720 for High Strength Disk Applications." Superalloys 1984, (Warrendale, PA: The metallurgical Society, 1984), 573-582, M. Gell, et al., eds.

2) K.R. Bain, M.L. Gambone, J.M. Hyzak, and M.C. Thomas, "Development of Damage Tolerant Microstructures in UDIMET 720", Superalloys 1988, (Warrendale, PA: The metallurgical Society, 1988), 13-22, D.N Duhl, et al., eds.

3) A. Cooper and J.K. Tien, "Grain Boundary Phases in an Advanced High Strength Superalloy", (unpublished work).

4) C.T. Sims, "Prediction of Phase Composition", Superalloys II (New York, New York :John Wiley \& Sons, 1987), 217-240, C.T. sims, et al., eds.

5) J.A. Domingue, internal memorandum, Special Metals Corporation, 18 February 1982.

6) K.A. Nabinger, "Sigma in U720" (Report JSM-88-150, Special Metals Corporation, 1988).

7) H.B. Canada, "Heat 6-5167" (Report CSR-162, Special Metals Corporation, 1969).

8) H.B. Canada, "U710, 7-4027-B, Test Bars" (Report N15-T-T1-T0, Special Metals Corporation, 1970). 